\title{
Development of Inhibitory Synapses Among Striatal Neurons in vitro
}

\author{
Janet M. Dubinsky \\ Departments of Pediatrics and Anatomy and Neurobiology, Washington University School of Medicine, St. Louis, Missouri \\ 63110
}

The development of excitatory and inhibitory synaptic connections has been studied in postnatal neurons from the caudate and putamen maintained in tissue culture. Excitatory postsynaptic potentials which were sensitive to the glutamate antagonist CNQX (6-cyano-7-nitroquinoxaline-2,3dione) appeared between 4 and $8 \mathrm{~d}$ in vitro. This is the first indication that glutamatergic excitatory neurons may be intrinsic to the striatum. Spontaneous inhibitory postsynaptic currents appeared at approximately the same time, several days after process outgrowth. Antibodies to glutamic acid decarboxylase (GAD), the synthetic enzyme for GABA, labeled neurons which produce bicuculline-sensitive, inhibitory postsynaptic currents. GAD immunoreactivity and immunoreactivity to synapsin I, a synaptic vesicle-associated protein, became localized to discrete sites along neurites 4-8 d after plating. It is concluded that the punctate GAD immunoreactivity identified possible sites of presynaptic transmitter release.

The synaptic organization of the striatum has been difficult to resolve using standard neuroanatomical techniques. The lack of a simple laminar architecture makes it difficult to predictably evoke and record synaptic potentials, as in the hippocampal slice. The presence of many histochemically identified GABAergic interneurons and projection neurons makes it likely that the majority of the intrinsic striatal neurons are inhibitory (Mugnaini and Oertel, 1985). However, physiologically this has been difficult to verify in both in vivo or in vitro preparations (Lighthall et al., 1981; Lighthall and Kitai, 1983). Because of this difficulty, synaptic transmission among striatal neurons has been studied in dissociated cultures from postnatal animals.

Since the majority of neurons are expected to use GABA as a transmitter, inhibitory responses attributable to GABA have been examined. Hippocampal inhibitory responses consist of both $\mathrm{GABA}_{\mathrm{A}}$ and $\mathrm{GABA}_{\mathrm{B}}$ hyperpolarizing potentials (Gahwiler and Brown, 1985; Newberry and Nicoll, 1985) and depolarizing $\mathrm{GABA}_{\mathrm{A}}$ potentials localized to dendrites and present in immature tissue (Andersen et al., 1980; Alger and Nicoll, 1982; Mueller et al., 1984; Huguenard and Alger, 1986). Any or all

\footnotetext{
Received Feb. 21, 1989; revised May 16, 1989; accepted May 17, 1989.

I wish to thank Drs. Steven M. Rothman and David I. Gottlieb for support, stimulating conversation, and critical reading of the manuscript. I gratefully acknowledge the assistance of Ms. Nancy Lancaster in preparation of the cultures and immunocytochemistry. This work was funded by grants from the Monsanto Corporation and NINCDS 19988 to S. M. Rothman and NINCDS 12867 to D. I. Gottlieb.

Correspondence should be addressed to Janet M. Dubinsky, $\mathrm{Ph} . \mathrm{D}$., Department of Anatomy and Neurobiology, Box 8108, Washington University School of Medicine, 660 S. Euclid Ave., St. Louis, MO 63110.

Copyright (C) 1989 Society for Neuroscience $0270-6474 / 89 / 113955-11 \$ 02.00 / 0$
}

of these types of GABA conductances may be present in striatal tissue. These experiments examined the development of the inhibitory synaptic interactions using both electrophysiological and immunocytochemical techniques. Additionally, fast excitatory synaptic activity was studied electrophysiologically.

\section{Materials and Methods}

Cell culture. Primary cultures of neurons and glia from the anterior caudate and putamen of 1- or 2-d-old postnatal rat pups were prepared according to modifications of established procedures (Huettner and Baughman, 1986; Nakajima et al., 1986). Caudate putamen (CP) was dissected out of coronal slices anterior to the appearance of the third ventricle as a roughly circular area posterior to the forceps minor of the corpus callosum, ventral and medial to the corpus callosum and lateral to the lateral ventricles. Acetylcholinesterase staining of sections taken midway through the dissected portion revealed that only caudate and putamen tissue were included (Fig. 1). Only a small amount of callosal tissue was apparent on the dorsal and lateral edges. Minced tissue was incubated in $1 \mu \mathrm{g} / \mathrm{ml}$ papain (Sigma Type IV) in L-15 for $20 \mathrm{~min}$ before gentle trituration. The resulting cell suspension was centrifuged through L-15 containing $10 \mu \mathrm{g} / \mathrm{ml} \mathrm{BSA}$ and $10 \mu \mathrm{g} / \mathrm{ml}$ trypsin inhibitor (Sigma). Cells were resuspended and plated $(350,000 / 35 \mathrm{~mm}$ dish) onto existing glial feeder layers in MEM without glutamine containing 10\% Nu Serum (this includes fibroblast growth factor, Collaborative Research), 20 units/ $\mathrm{ml}$ penicillin, and $20 \mu \mathrm{g} / \mathrm{ml}$ streptomycin. Cells were maintained at $37^{\circ} \mathrm{C}$ in a humidified atmosphere of $95 \%$ air and $5 \% \mathrm{CO}_{2}$. Twenty-four hours after plating, each dish received an aliquot of fluorodeoxyuridine and uridine to final concentrations of 15 and $35 \mu \mathrm{g} / \mathrm{ml}$, respectively.

Glial cells were dissociated from 2-d-old rat pups from either cerebral cortex or caudate-putamen according to Nobel et al. (1984) and plated in T25 flasks in MEM supplemented as above. After 1 week the flasks were washed vigorously with cold L15 to remove surviving neurons and fed with supplemented MEM with $15 \mu \mathrm{g} / \mathrm{ml}$ fluorodeoxyuridine and $35 \mu \mathrm{g} / \mathrm{ml}$ uridine. Glial flasks were fed on a weekly basis for 1-7 weeks until passaged onto $35 \mathrm{~mm}$ polylysine-coated plastic petri dishes $4 \mathrm{~d}$ before neuronal plating. For fluorescence staining, cells were plated onto polylysine- and collagen-coated glass coverslips, glass insets in plastic petri dishes, or 8 chamber glass slides (Lab-Tek).

Electrophysiology. Individual CP neurons were voltage clamped with patch electrodes in whole-cell recording mode (Hamill et al., 1981) with an Axopatch 1B amplifier (Axon Instruments). Internal and external solutions are listed in Table 1. Data acquisition and voltage-step generation were controlled from the SPIKE program(Hillal Associates) through a Modular Instruments Inc. analog-digital converter connected to an IBM-AT computer. Because of the difficulty in maintaining adequate voltage control over the extensive processes of older cells, cells were voltage-clamped to $-60 \mathrm{mV}$ initially and only stepped briefly to voltages between -30 and $-90 \mathrm{mV}$. Voltages reported here include a $6 \mathrm{mV}$ correction for junction potentials developed by the low chloride internal solutions. Holding currents for cells less than 1 week in vitro were typically 10-20 pA, while for older cells, holding currents increased up to $100 \mathrm{pA}$. Cells with holding currents above $100 \mathrm{pA}$ were discarded. Cell capacitance was calculated by integrating the current response to the offset of a $-10 \mathrm{mV}$ voltage step. Spontaneous activity was recorded onto a Gould chart recorder or Gould model 6504 FM tape recorder. GABA, bicucullin, and CNQX were applied by brief pressure pulses from a patch pipet positioned $10-20 \mu \mathrm{m}$ from a cell soma. Cells were allowed to recover for $40 \mathrm{sec}$ between GABA applications to prevent 


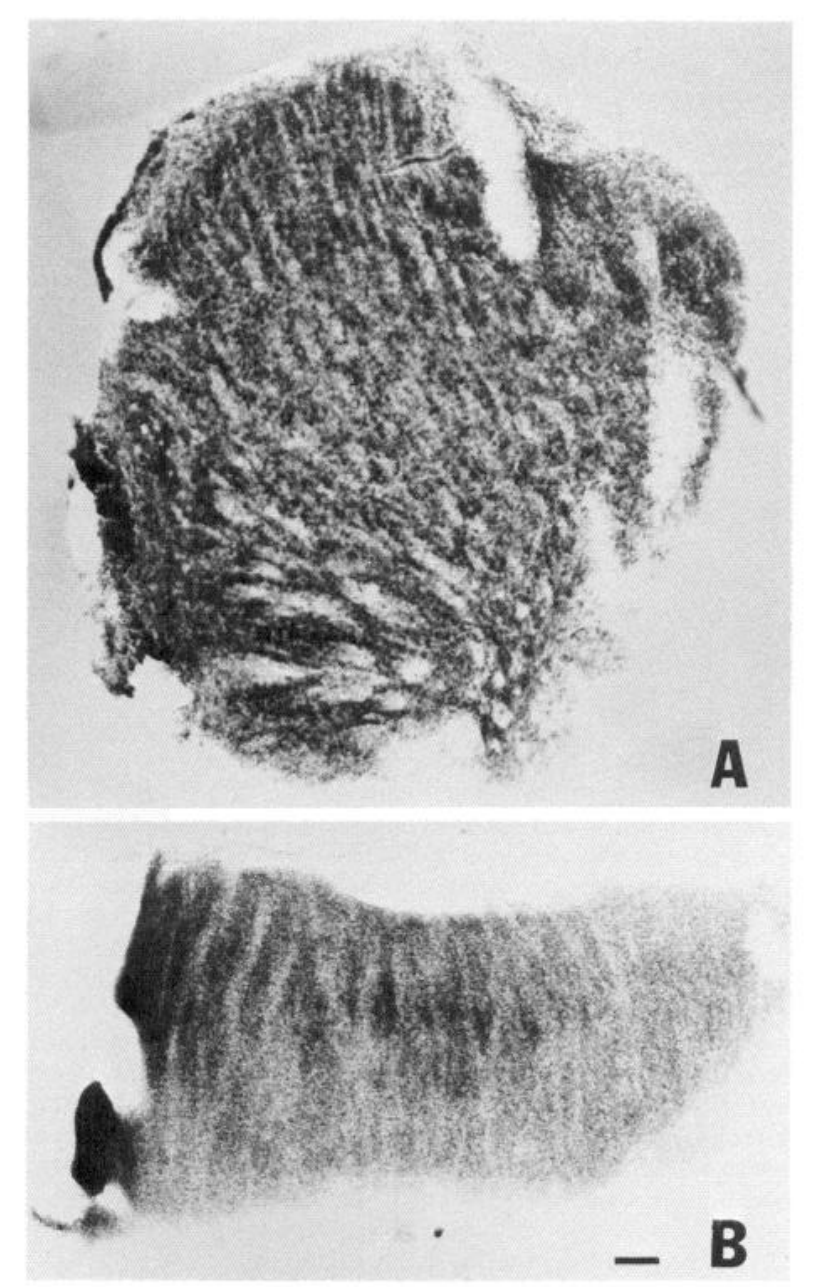

Figure 1. Acetylcholinesterase-stained sections $(100 \mu \mathrm{m})$ through a portion of neonatal rat brain used in caudate-putamen dissections. "Striated" nature of the tissue is apparent in both coronal $(A)$ and horizontal $(B)$ sections (compare with Paxinos and Watson, 1986). Ventricular (medial) edge is at left, lateral at right. Dorsal is at the top in $A$, and anterior is at the top in $B$. Scale bar, $100 \mu \mathrm{m}$.

desensitization. Ten millimolar stock solutions of CNQX (Tocris Neuramin, London) were made up in equimolar $\mathrm{NaOH}$ in water and diluted in external recording solution prior to use.

Synaptically coupled cell pairs were recorded using whole-cell patch clamping for the postsynaptic cell and extracellular stimulation of loosely sealed patch electrodes on the presynaptic cell (Dubinsky et al., 1988) The presynaptic patch electrode was connected to an A-M Systems Neuroprobe Amplifier model 1600 and contained internal solution in case intracellular contact was made. Pairs of phase-bright cells within $200 \mu \mathrm{m}$ of each other with interposed neurites were chosen to test for synaptic interactions. All recordings were performed at room temperature. Synaptic connections were defined as monosynaptic if the latency from the peak of the presynaptically recorded action current to the onset of the postsynaptic current was $<5.0 \mathrm{msec}$ and varied by $<0.7 \mathrm{msec}$ between trials (sampling period $0.33 \mathrm{msec}$ ). Hirano et al. (1986) have measured the Q10 for monosynaptic connections among cultured cerebellar neurons and have shown that latencies $<6 \mathrm{msec}$ at $23^{\circ} \mathrm{C}$ correspond to $1 \mathrm{msec}$ or less at $37^{\circ} \mathrm{C}$. Many CP connections could follow high-frequency stimulation up to $20 \mathrm{~Hz}$, but not all connections were tested in this manner since depression was frequently observed.

Immunocytochemistry. The staining procedures for the monoclonal antibody, GAD-6 (Chang and Gottlieb, 1988; kindly provided by Dr. David I. Gottlieb) and polyclonal antibody to synapsin I (De Camilli et al., 1983; kindly provided by Dr. Paul Greengard) were as follows. Initially, cells were fixed for $10 \mathrm{~min}$ in warm $4 \%$ paraformaldehyde and
Table 1. Electrophysiological solutions

\begin{tabular}{lccccc} 
& \multicolumn{1}{l}{ A } & & & B \\
\cline { 2 - 3 } \cline { 5 - 6 } Solute & External & Internal & & External & Internal \\
\hline $\mathrm{NaCl}$ & 126.8 & - & & 140.0 & - \\
$\mathrm{KCl}$ & 13.2 & 13.7 & & 8.0 & 2.0 \\
$\mathrm{~K}-$ isethionate & - & 126.3 & & - & 138.0 \\
$\mathrm{CaCl}_{2}$ & 2.0 & - & & 2.0 & - \\
$\mathrm{MgCl}_{2}$ & 1.0 & - & & 1.0 & - \\
$\mathrm{Na}-\mathrm{Hepes}$ & 10.0 & 10.0 & & 10.0 & 10.0 \\
Glucose & 50.0 & 40.0 & & 40.0 & 40.0 \\
MgATP & - & 2.0 & & - & 2.0
\end{tabular}

Concentrations in mM.

$0.1 \%$ glutaraldehyde in L- 15 . Following extensive rinsing in L- 15 , cells were incubated for $30 \mathrm{~min}$ in $20 \mathrm{~mm}$ Sorenson's phosphate buffer containing $0.1 \%$ glycine. Subsequently, primary antibody diluted (1:800 GAD-6, 1:400 anti-synapsin I) in $20 \mathrm{~mm}$ Sorenson's phosphate buffer with $0.45 \mathrm{M} \mathrm{NaCl}, 0.2 \%$ Triton $\mathrm{X}-100,10 \%$ normal goat serum, and $0.1 \% \mathrm{Na}$ azide was applied for $1 \mathrm{hr}$ at room temperature. After rinsing in the buffer formulated above, cells were incubated in fluoresceinconjugated secondary antibodies for $1 \mathrm{hr}$ (FITC-goat anti-mouse IgG and IgM, Cappel, for GAD-6 and FITC-goat anti-rabbit IgG, Boehringer-Mannheim, for synapsin I). Cells were rinsed for $30 \mathrm{~min}$ in buffer, followed by 3 rinses in $5 \mathrm{~mm}$ Sorenson's phosphate with $25 \mathrm{~mm}$ sucrose before mounting in a glycerol-PBS mixture that prevents bleaching (Citifluor). Substitution of normal mouse serum for GAD-6 or normal rabbit serum for anti-synapsin I for the primary antibodies or omission of the primary antibodies resulted in an absence of fluorescence staining in all experiments. Preabsorption of anti-synapsin I with $1.8 \mu \mathrm{g} / \mathrm{ml}$ synapsin I also produced no detectable fluorescence signal. In doublelabeling experiments, rhodamine-conjugated goat anti-mouse IgG (Jackson Immunocytochemicals) was used to visualize GAD-6. No crosslabeling was observed of either secondary antibody for the inappropriate primary antibody or normal control serum. No cell surface GAD-6 immunoreactivity was observed when live cultures were incubated with mAb GAD-6 (1:200, but see Docherty et al., 1987).

Immunostaining for the presence of GABA was performed with affinity-purified antibodies to GABA conjugated to BSA (GABA-5; Wenthold et al., 1986; kindly provided by John Zemple). After the above fixation, cells were incubated for $30 \mathrm{~min}$ in $0.1 \mathrm{M}$ phosphate buffer with $5 \%$ normal goat serum and $0.2 \%$ Triton X-100. GABA- 5 antibody was diluted 1:200 in this buffer and applied for $1 \mathrm{hr}$ at room temperature. After rinsing, cells were incubated in fluorescein-conjugated goat antirabbit IgG (Boehringer-Mannheim) for $1 \mathrm{hr}$. Subsequently, cells were rinsed and mounted as above. No fluorescence signal was observed when normal rabbit serum was substituted for GABA-5, when the primary antibody was omitted, or when GABA-5 was preabsorbed with GABAconjugated to ovalbumin.

While these antibodies are well characterized (GAD-6 and anti-synapsin I both recognize single bands on gels: Chang and Gottlieb, 1988; De Camilli et al., 1983), the possibility remains that they may be recognizing some similar, as yet unidentified cellular antigen. Therefore, although the terms GAD-6, GABA-5, or synapsin I immunoreactivity are used throughout this paper, they should be interpreted to mean GAD-like, GABA-like, and synapsin I-like immunoreactivity.

Cultures were initially stained with antibodies directed against neuron-specific enolase (NSE, ICN Immunobiclogicals), phosphorylated and nonphosphorylated neurofilaments (SMI 31 and SMI 32, Sternberger-Meyer Immunocytochemicals, Inc.), and glial-fibrillary acidic protein (GFAP; Bignami et al., 1972) to differentially identify neurons and astrocytes. All phase-bright ovoid or pyramidal shaped cells with 2-5 long, thin, relatively straight processes and eccentric nuclei stained positively for NSE, SMI 31, or SMI 32 and were identified as neurons. All large, flat, spread cells stained positively for GFAP and were classified as astrocytes. A small population of mostly flat, phase-dark cells with multiple, thick, short, crooked processes, possibly oligodendroglia, remain to be positively identified. These cells were excluded from electrophysiological and immunocytochemical experiments. SMI 31 and SMI 32 staining of the glial feeder layers was performed to confirm the 


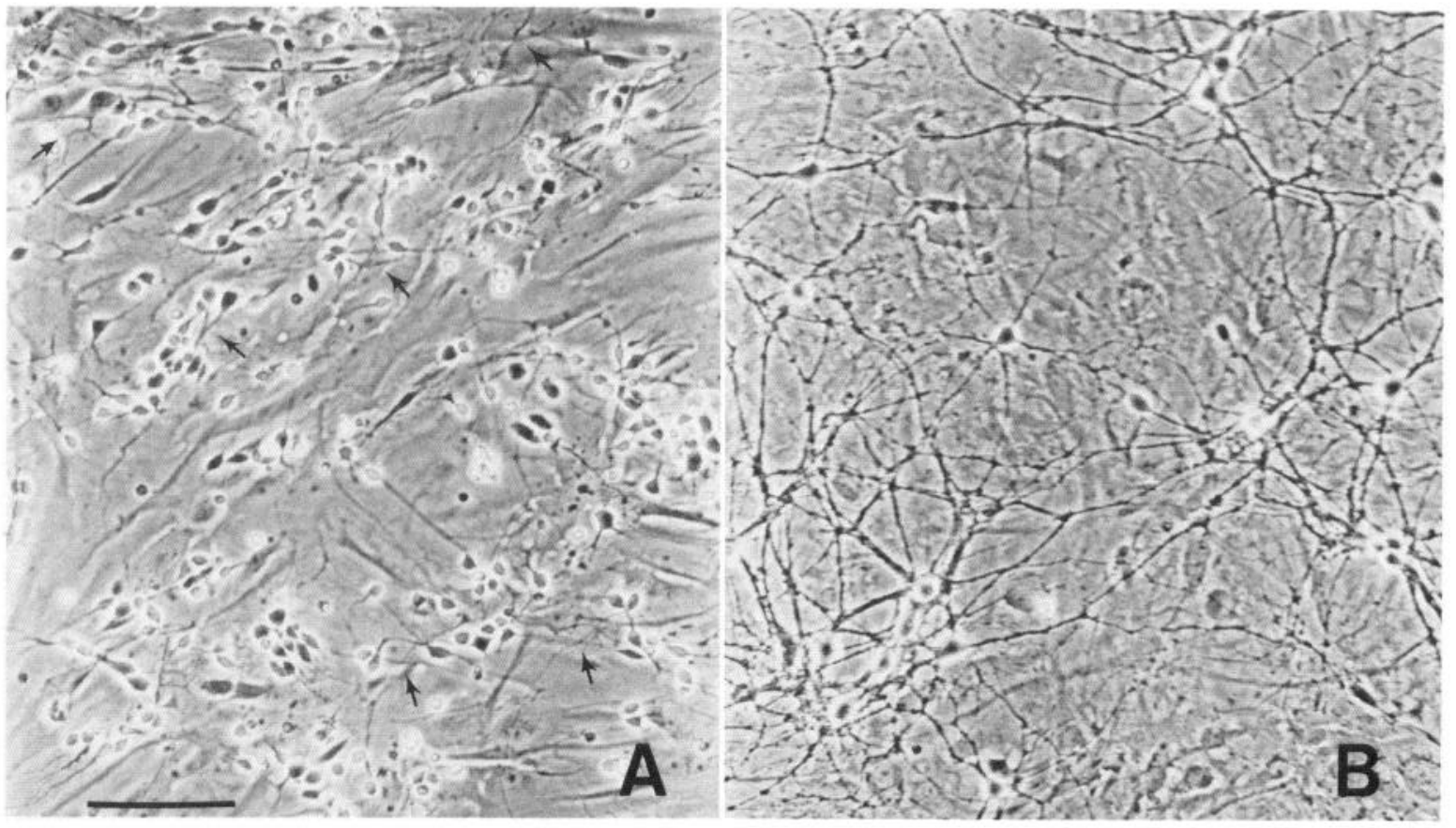

Figure 2. Phase-contrast micrographs of neonatal striatal neurons maintained in vitro. A, Neuritic process extension (arrows) 24 hr after plating. $B$, Appearance of mature cultures with fasciculated processes and large phase-bright neurons, in this case 7 weeks in vitro. Scale bar, $100 \mu \mathrm{m}$.

removal of all cortical neurons. Only 9 poorly developed cells with possible neuronal profiles were immunoreactive on 14 dishes from 2 separate glial platings. Cells with such an unhealthy appearance were not used for electrophysiology.

\section{Results}

Survival of striatal neurons in culture

The photomicrographs in Figure 2 show dissociated CP neurons maintained in culture for $24 \mathrm{hr}$ and 7 weeks. Within $4 \mathrm{hr}$ after dissociation, CP neurons attached to the glial feeder layer and began to extend processes. By $24 \mathrm{hr}$, these processes contacted neurites and somas of other neurons. Over the next week, process extension continued, forming a meshwork of interconnecting fascicles over the glial substrate. During this time, culture appearance changed sufficiently that positive identification of the same neuron was not possible with daily photographic observation. Clumps of neuronal cell bodies often formed in the denser portions of some cultures. After a week, the cultures appeared to stabilize and relocation of identified neurons on subsequent days was possible. Cultures maintained this healthy appearance for 4-7 weeks in vitro. The appearance of grainy neurites and abruptly truncated processes indicated that cultures were dying. Once this occurred, no phase-bright neurons remained after another week.

Neuronal survival was quantified by counting 10 representative fields per dish on successive days for several different platings (Fig. 3). Over $50 \%$ of the plated neurons died between days 4 and 8 in vitro. After 2 weeks, the number of surviving neurons stabilized.

\section{Spontaneous activity}

By electrophysiological criteria, CP neurons appeared healthy at all ages in vitro. Stable recordings could be obtained from several hours up to 4 weeks after plating. The parallel combination of input resistance and electrode seal resistance was 1.2 $\pm 1.3 \mathrm{G} \Omega(N=72)$. The average resting potential in solution $\mathrm{A}$ was $54.0 \pm 8.0 \mathrm{mV}$ (mean $\pm \mathrm{SD}, N=61)$. This decreased from $-58.0 \pm 10.0 \mathrm{mV}$ at $1 \mathrm{~d}$ in vitro (div) to $-49.5 \pm 3.6 \mathrm{mV}$ (13) in the third week after plating. Fast overshooting action potentials, sometimes accompanied by afterhyperpolarizations, were observed in $77 \%$ of striatal neurons after 1 div, increasing to $100 \%$ of neurons after day 8 .

Synaptic activity was classified as excitatory or inhibitory according to the following criteria. Postsynaptic currents which were outward above $-60 \mathrm{mV}$, reversed at $-60.9 \pm 2.1 \mathrm{mV}$ (solutions B), and were blocked by $100 \mu \mathrm{M}$ bicuculline were considered to be inhibitory postsynaptic currents (IPSCs). In-

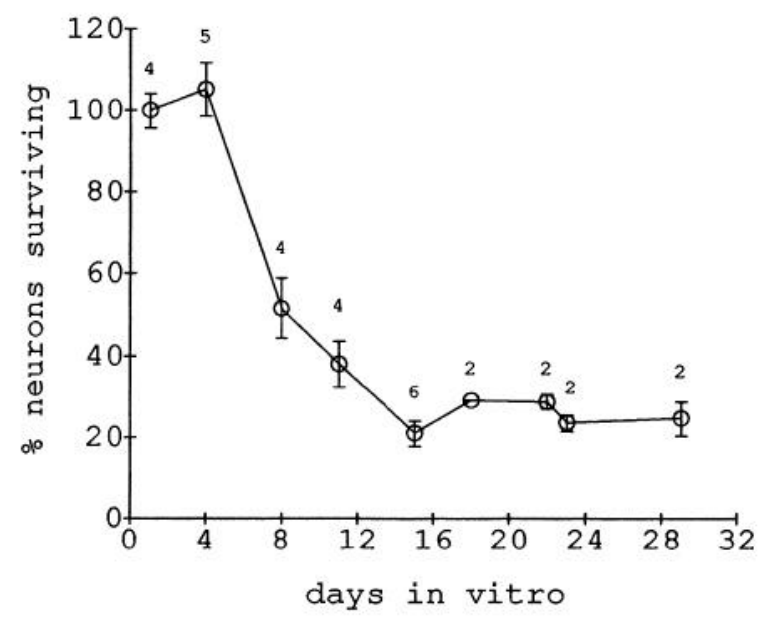

Figure 3. Survival of neonatal CP neurons in long-term cultures. Number of platings counted at each time point are indicated. Numbers expressed as percentage of neurons present on day 1 (means \pm SEM). Initially, a $350 \times 250 \mu \mathrm{m}$ field contained an average of 450 neurons. 


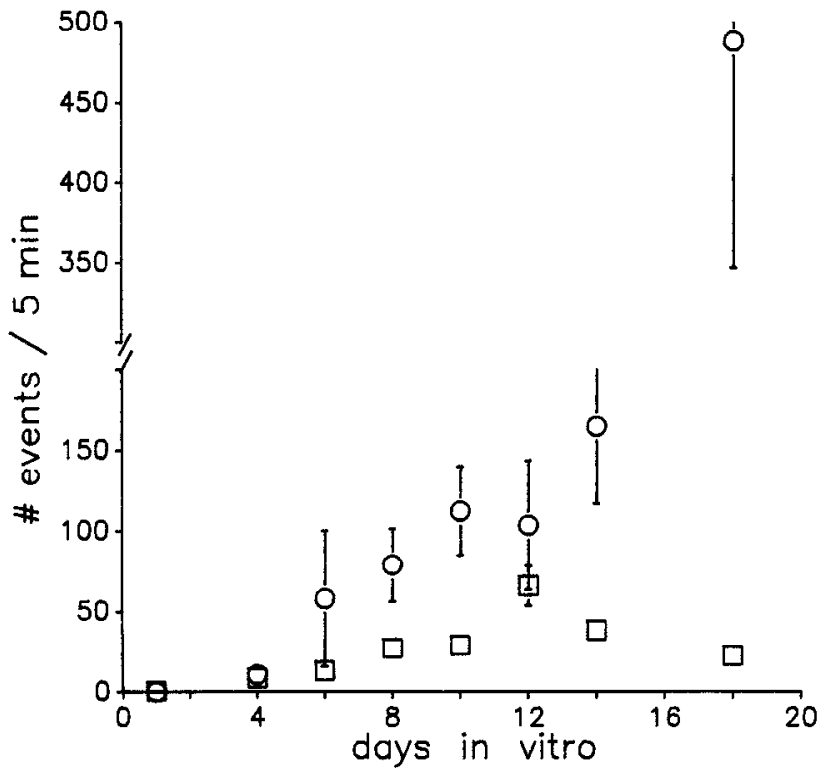

Figure 4. Development of spontaneous synaptic activity in CP cultures. The number of spontaneously occurring excitatory (circles) and inhibitory (squares) postsynaptic currents were recorded during $5 \mathrm{~min}$ at -60 and $-40 \mathrm{mV}$, respectively. Numbers are mean $\pm S E M$, in solution $B$.

ward postsynaptic currents which could not be reversed at negative holding potentials and were blocked by $200 \mu \mathrm{M}$ CNQX (Yamada et al., 1989) were considered to be excitatory postsynaptic potentials (EPSCs).

A low incidence of spontaneous synaptic activity could be observed in $17 \%$ of cells $1 \mathrm{~d}$ after plating. By day $4,67 \%$ of all cells had EPSCs and 74\% exhibited IPSCs. The number of spontaneous EPSCs increased steadily with age in vitro (Fig. 4), while the number of IPSCs increased up to 12 div and subsequently declined. Spontaneous synaptic activity persisted unchanged in the presence of $1 \mu \mathrm{g} / \mathrm{ml} \mathrm{TTX} \mathrm{(sufficient} \mathrm{to} \mathrm{block} \mathrm{all} \mathrm{sodium}$ action potentials) through day 8 . After day 10 , TTX reduced the frequency of spontaneous events.

Evoked synaptic activity recorded from pairs of cultured neurons was encountered reliably during the third week in vitro. Fourteen percent ( 4 out of 29) of all pairs of neurons impaled on day 8 were synaptically coupled. This incidence increased to $61 \%(16 / 26)$ by day 14 .

\section{Postsynaptic response}

$\mathrm{CP}$ neurons responded to GABA at all ages studied. Postsynaptic responses to pressure application of $100 \mu \mathrm{M}$ GABA were recorded for membrane holding potentials between -90 and -30 $\mathrm{mV}$ in solutions A. Current-voltage plots of these responses were generally linear, although some exhibited rectification at potentials below $-70 \mathrm{mV}$ (Fig. $5 C$, filled circles). Responses to GABA reversed at the same membrane potential as synaptically driven inhibitory currents (Fig. 5). In order to evaluate postsynaptic sensitivity to GABA, the slope conductance was calculated from the current-voltage plot between -70 and -30 $\mathrm{mV}$. The slope conductance increased over time (Fig. 6A). However, when these values were normalized to cell capacitance to correct for neuronal size, no developmental increase was detected (Fig. $6 B$ ). The $\mathrm{GABA}_{\mathrm{B}}$ receptor agonist baclofen $(100 \mu \mathrm{M})$ did not alter membrane current in this same voltage range $(N$ $=8$ ). Application of GABA to proximal processes produced smaller-amplitude, slower-rising responses that reversed at the same potential as somal application.

\section{Presynaptic maturation}

In order to study the development of presynaptic structures, a reliable marker for presynaptic inhibitory neurons was needed.

Figure 5. Inhibitory postsynaptic currents $(B$, open circles in $C)$ reversed at the same membrane potential as pressure-applied $100 \mu \mathrm{M}$ GABA $(A$, filled circles in $C)$. $A$ and $B$ are from the same cell recorded in solution $B$. Lower trace in $A$ indicates GABA application; lower trace in $B$ is extracellularly recorded action current. Scale bar, $25 \mathrm{msec}, 60 \mathrm{pA}$ in $A ; 10 \mathrm{msec}, 60 \mathrm{pA}, 10 \mathrm{pA}$ in $B$.
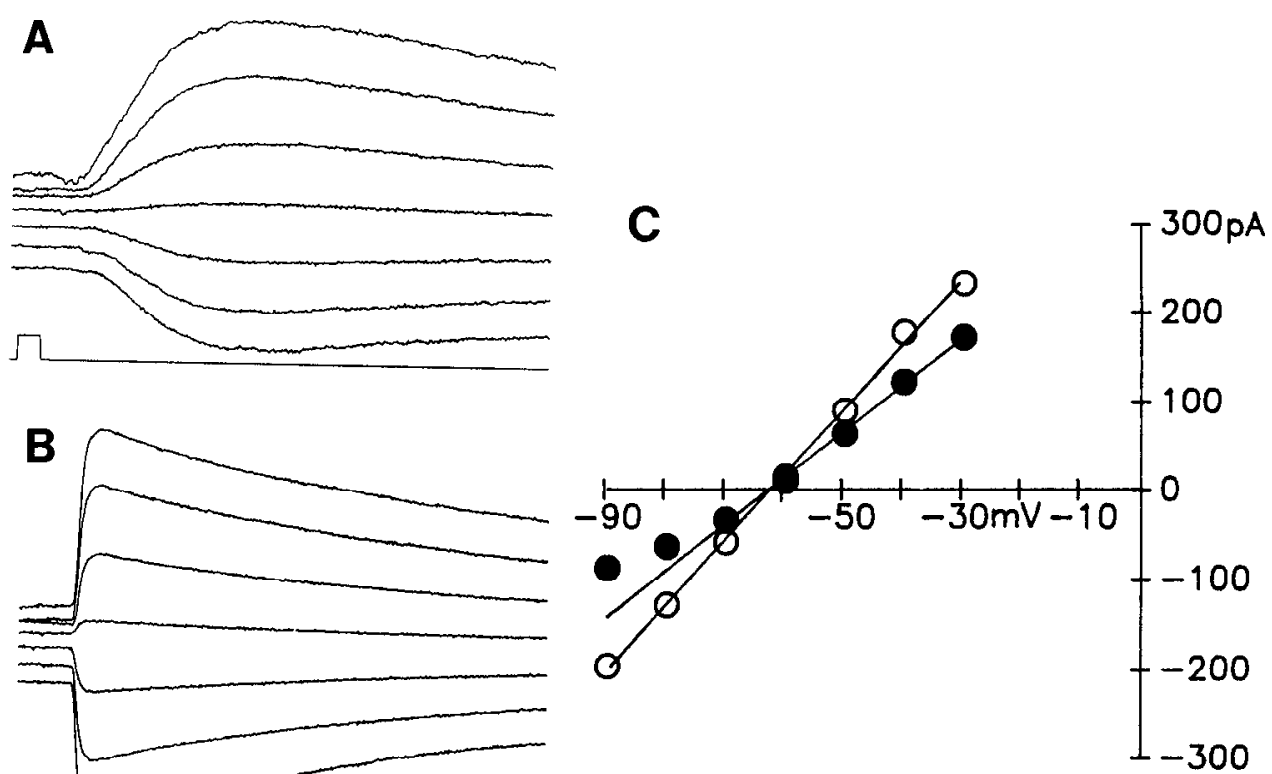
$\mathrm{GAD}$, the synthetic enzyme for GABA, has typically been employed to locate putative inhibitory neurons. However, it is not known if GAD is an exclusive marker or if it is also present in other non-GABA-releasing neurons. To test this possibility, electrophysiologically identified, monosynaptically coupled pairs of neurons were subsequently stained for GAD with a monoclonal antibody (GAD-6; Chang and Gottlieb, 1988). GAD-6 immunofluorescence was scored by 2 observers, including one who had no knowledge of the electrophysiological results.

As expected, in $92 \%(N=12)$ of monosynaptic (latency $<5.0$ $\mathrm{msec}$ ) inhibitory connections, the presynaptic neuronal soma was immunoreactive for GAD-6 (Fig. 7A). In presynaptic excitatory neurons, GAD-6 immunoreactivity was absent $77 \%(N$ $=13$ ) of the time (Fig. $7 B$ ). In 3 instances, excitatory presynaptic neurons (synaptic latencies $0.9,2.0$, and $3.1 \mathrm{msec}$ ) contained immunoreactivity for GAD-6 (Fig. 7C). Overall, 79\% (11/14) of GAD-6-positive presynaptic neurons were indeed inhibitory. Only $9 \%(1 / 11)$ of unstained presynaptic neurons produced bicuculline-sensitive inhibitory postsynaptic currents. ${ }^{1}$

Presynaptic maturation was therefore examined using the GAD-6 antibody. GAD-6 immunoreactivity was also correlated with immunoreactivity to antibodies directed against both synapsin I, a synaptic vesicle-associated protein (De Camilli et al., 1983) and GABA conjugated to glutaraldehyde (GABA-5; Wenthold et al., 1986). GAD-6 stained neurites and cytoplasmic portions of the majority of CP somas (Fig. 8). The intensity of somal staining was increased by overnight pretreatment with 1 $\mu \mathrm{g} / \mathrm{ml}$ colchicine in the growing medium (Fig. $8 B$ ). The proportion of somas exhibiting GAD-6 immunofluorescence remained constant at all ages examined (Fig. 8C). Colchicine pretreatment did not alter the number of GAD-6-positive neurons detected.

In mature cultures, synapsin I immunoreactivity has been localized to discrete areas along neuritic processes (Weiss et al., 1986). When cultures were stained simultaneously for synapsin I and GAD-6, the punctate GAD-6 immunoreactivity exactly colocalized with the punctate synapsin I immunofluorescence (Fig. 9). As expected, some processes staining positively for synapsin I did not contain any GAD-6 immunoreactivity.

Developmentally, however, the patterns of GAD-6 and synapsin I immunoreactivity differed slightly (Fig. 10). Initially, GAD-6 immunoreactivity was observed only in neuronal somas in asymmetric patterns resembling cytoplasmic (non-nuclear) areas. At this time, synapsin I staining was found uniformly distributed in somas and along processes. In the next few days, synapsin I became increasingly localized to small discrete areas along neurites and the somal staining becamc less prominent but did not disappear. In some cells during the first week, GAD-6 immunoreactivity appeared uniform throughout the soma and processes. More often, GAD-6 immunofluorescence became progressively more localized to neuritic puncta. Colocalization experiments suggested that synapsin I puncta developed before the GAD- 6 puncta, but quantitative intensity measurements were not attempted. In contrast to GAD-6 immunufluorescence,

${ }^{1}$ mAb GAD-6 labeled $66.7 \%(n=33)$ of postsynaptic somas, a proportion comparable to the number of GAD-6-labeled cells overall (see Fig. $8 \mathrm{C}$ ). Since the whole-cell recording technique was invariably employed for postsynaptic recording, internal dialysis of cellular contents did not compromise the GAD-6 immunostaining. Every attempt was made to stimulate presynaptic cells extracellularly to insure intact cytoplasmic contents. However, in the few instances where intracellular recording was unavoidable, the immunocytochemical results were accepted as valid because of the clear presence of GAD-6 stain in postsynaptic cells.
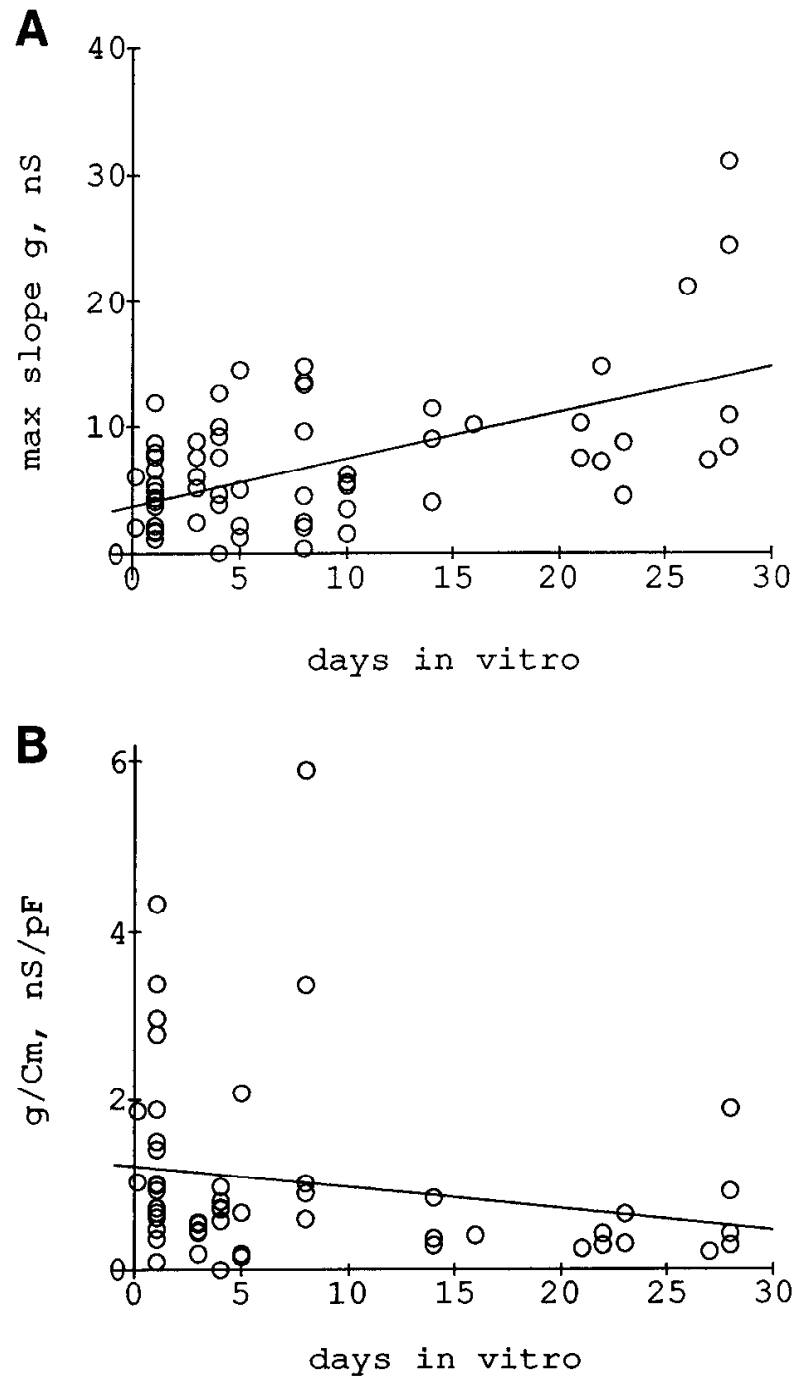

Figure 6. Sensitivity of CP neurons to pressure-applied GABA. $A$ Maximum slope conductance for 66 neurons appears to increase with age. $B$, Same data as $A$, normalized for cell capacitance. Slope of linearregression line does not significantly differ from $0(t$ test, $p=0.15$, solution A).

GABA-5 staining was uniform throughout the soma and processes of $\mathrm{CP}$ neurons. The percentage of GABA-5-positive neurons increased from $40 \%$ at 1 div to $90 \%$ by the end of the first week.

The appearance of discrete puncta of GAD-6 immunoreactivity around neuronal somas is presented in Figure 11. The time course of their appearance resembles the time course of onset of spontaneous synaptic activity (Fig. 4). To test this correlation, GAD-6 immunostaining was performed after electrophysiological recording of spontaneous activity on identified cells. In 29 neurons with spontaneous IPSCs, punctate GAD-6 immunostaining was always present in processes adjacent to the soma or proximal neurites. Ten out of 14 younger neurons with no spontaneous IPSCs ( 3 min of continuous recording at -40 $\mathrm{mV}$ ) lacked GAD-6 puncta adjacent to their somas or proximal processes. In the remaining 4 neurons without spontaneous IPSCs, only 1 or 2 appropriately placed, dim puncta could be observed. In these cases, it is conceivable that the observation period should have been extended in order to observe IPSCs. 

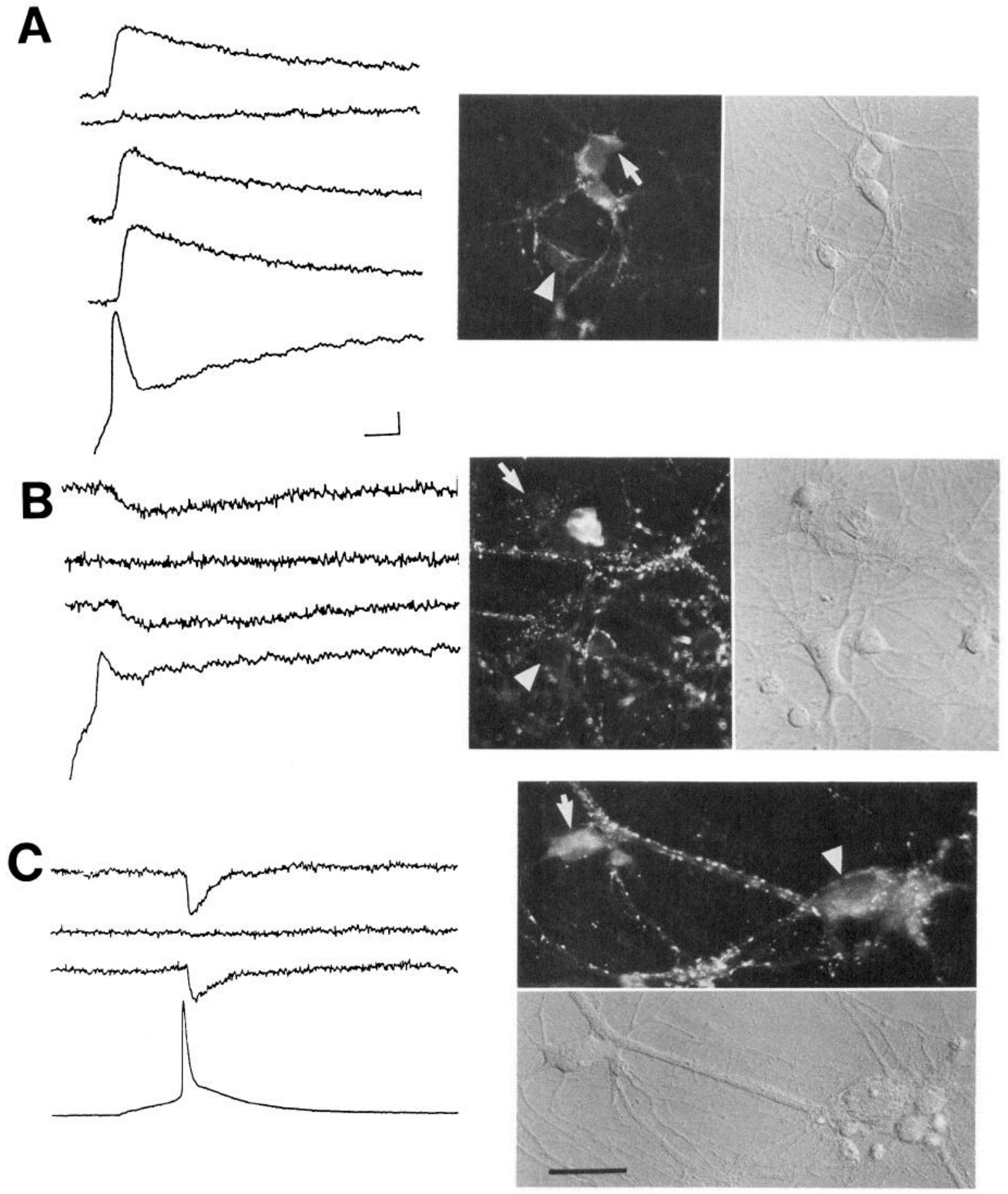

Figure 7. GAD-6 immunofluorescence of identified presynaptic (arrows) and postsynaptic (arrowhead) neurons. Evoked postsynaptic currents recorded at $-60 \mathrm{mV}$ (solution B) are offset to demonstrate block by appropriate antagonist. In fluorescence and differential interference contrast micrographs, scale bar, $50 \mu \mathrm{m}$. A, Presynaptic neuron producing a bicuculline-sensitive IPSC was GAD-6 positive. Traces are (top to bottom) control IPSC, IPSC after $100 \mu \mathrm{M}$ bicuculline, recovery, IPSC after $200 \mu \mathrm{M}$ CNQX, extracellular presynaptic action current stimulus. Scale bar, 10 $\mathrm{msec}, 10 \mathrm{pA}$. B. Presynaptic neurons producing a CNQX-sensitive synaptic response had no GAD-6 immunoreactivity. Traces are control EPSC, EPSC after $200 \mu \mathrm{M}$ CNQX, recovery, and extracellular action current stimulus. Scale bar, $10 \mathrm{msec}, 5$ pA. $C$, Presynaptic neuron with GAD-6 immunofluorescence produced a CNQX-sensitive postsynaptic response. Traces are control EPSC, EPSC after $200 \mu \mathrm{M}$ CNQX, recovery, and intracellular action potential stimulus. Scale bar, $15 \mathrm{msec}, 7.5 \mathrm{pA}, 10 \mathrm{mV}$.

No correlation was observed between the number of presynaptic puncta and the frequency of spontaneous IPSCs. The absence of such a relationship suggests that synaptic efficacy varies greatly among these putative presynaptic sites.

\section{Discussion}

These experiments demonstrate that in vitro striatal neurons exhibit glutamatergic excitatory activity and GABAergic inhib- 

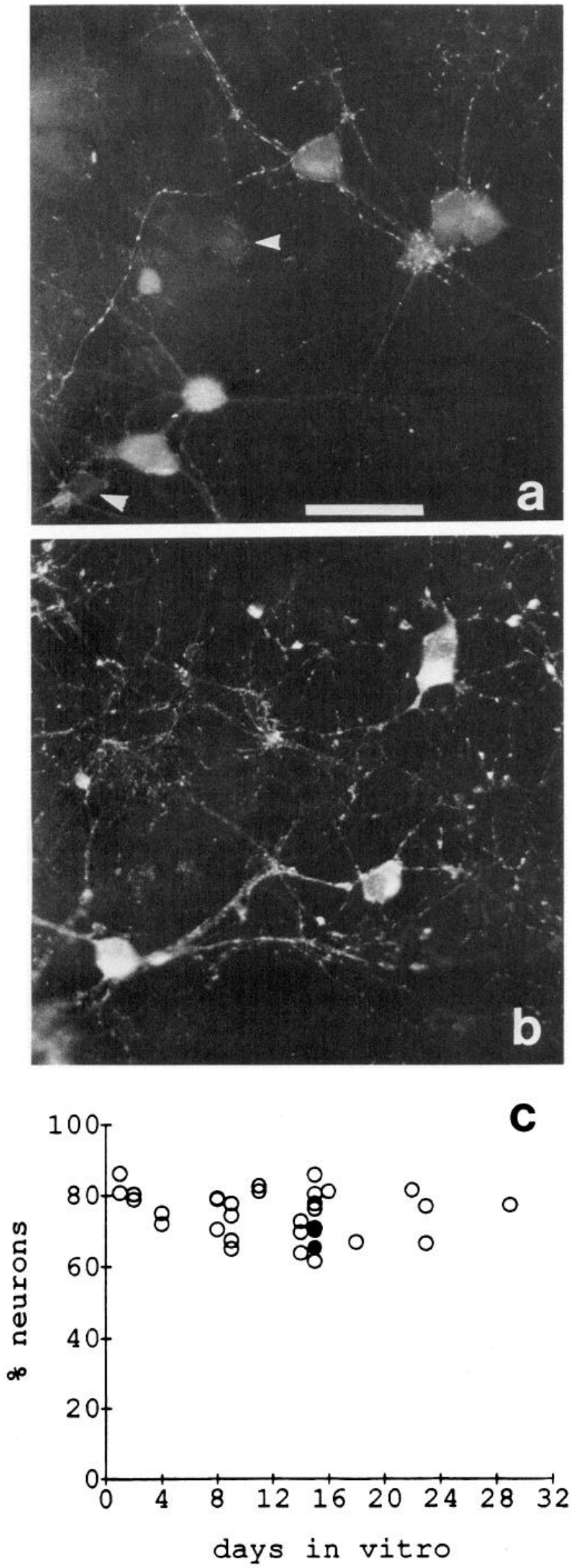

itory activity. Immunoreactivity to the GAD-6 antibody serves as a marker for inhibitory GABAergic neurons. The appearance of GAD-6 immunoreactivity in putative presynaptic sites corresponds to the onset of spontaneous inhibitory activity in these cultures.

\section{Survival of striatal neurons in vitro}

The death of a subpopulation of striatal neurons (not necessarily GABAergic) between days 4 and 8 in vitro may be attributable to several causes. In vivo, $25 \%$ of striatal neurons die during a period of naturally occurring cell death at $4-8 \mathrm{~d}$ postnatally (Fentress et al., 1981). Striatal cultures prepared from embryonic day 17 rat pups also show abrupt reductions in cell number immediately after plating but not at similar conceptual ages (Surmeier et al., 1988). While known growth factors have been supplied in the culture media (Morrison et al., 1987), unidentified growth factors may still be required for cell survival. Since $70 \%$ of striatal neurons project to other CNS structures (Bolam et al., 1981; Loopuijt and Van der Kooy, 1985), the absence of appropriate targets may adversely affect the survival of projecting neurons. Because the period of active synaptogenesis occurs simultaneously, the surviving population may be determined by their ability to form functional synaptic contacts with other intrinsic striatal neurons.

\section{GAD-6 immunoreactivity as marker for GABAergic cells}

Since the developmental observations reported in this paper depend heavily upon immunocytochemical labeling, it was necessary to clearly establish that the antigen recognized by the GAD-6 monoclonal antibody was a marker for inhibitory neurons. On Western blots of unfractionated rat whole brain, GAD-6 recognizes a single $59 \mathrm{kDa}$ protein that has been purified, sequenced, and shown to be homologous to the protein coded for by a cDNA for feline GAD (Chang and Gottlieb, 1988). Relocation of electrophysiologically identified synaptic pairs clearly demonstrated that mAb GAD-6 overwhelmingly labeled inhibitory neurons. This is the first confirmation of any immunocytochemical marker for GABAergic neurons. The absence of label in one 17-d-old inhibitory neuron may be attributable to the developmental decrease in somal labeling observed during the third week in vitro.

Two populations of GABAergic neurons have been reported in the striatum; those that stain lightly or intensely with probes for GAD (Oertel and Mugnaini, 1984; Chesselet et al., 1987; Kita and Kitai, 1988). Both of these populations are observed in culture and together account for $76 \%$ of all neurons. GADlike immunoreactivity in intact caudate and putamen is reported present in from $40-90 \%$ of all neurons (Penny et al., 1986; Mugnaini and Oertel, 1985), the most recent estimate being $85 \%$ (Kita and Kitai, 1988). Colchicine pretreatment, routinely used$$
\leftarrow
$$

Figure 8. GAD-6 immunofluorescence in CP neurons. $A$, The majority of neurons in this 15-d-old culture contained cytoplasmic GAD immunoreactivity. Unstained neurons indicated by arrowheads. B, Pretreatment of sister culture overnight with $1 \mu \mathrm{g} / \mathrm{ml}$ colchicine-enhanced cytoplasmic staining. Scale bar, $50 \mu \mathrm{m}$ for $A$ and $B$. $C$, Percentage of GAD-6 positive CP neurons remained constant over 4 weeks in vitro. Each symbol represents the percentage of GAD-6-positive neurons observed in 10 microscopic fields $(350 \times 250 \mu \mathrm{m})$. An average of $167 \pm$ $24(N=34$; range, $40-651)$ neurons was counted per point. Filled circles are from cultures pretreated with $1 \mu \mathrm{g} / \mathrm{ml}$ colchicine; open circles, untreated cultures.
} 
Figure 9. Colocalization of GAD-6 immunoreactivity with anti-synapsin I immunofluorescence in a 22-d-old culture. $A, \mathrm{mAb}$ GAD-6 visualized with a rhodamine-conjugated goat anti-mouse IgG. $B$, Synapsin I immunofluorescence visualized with a fluorescein conjugated goat anti-rabbit IgG. Scale bar, $50 \mu \mathrm{m}$.
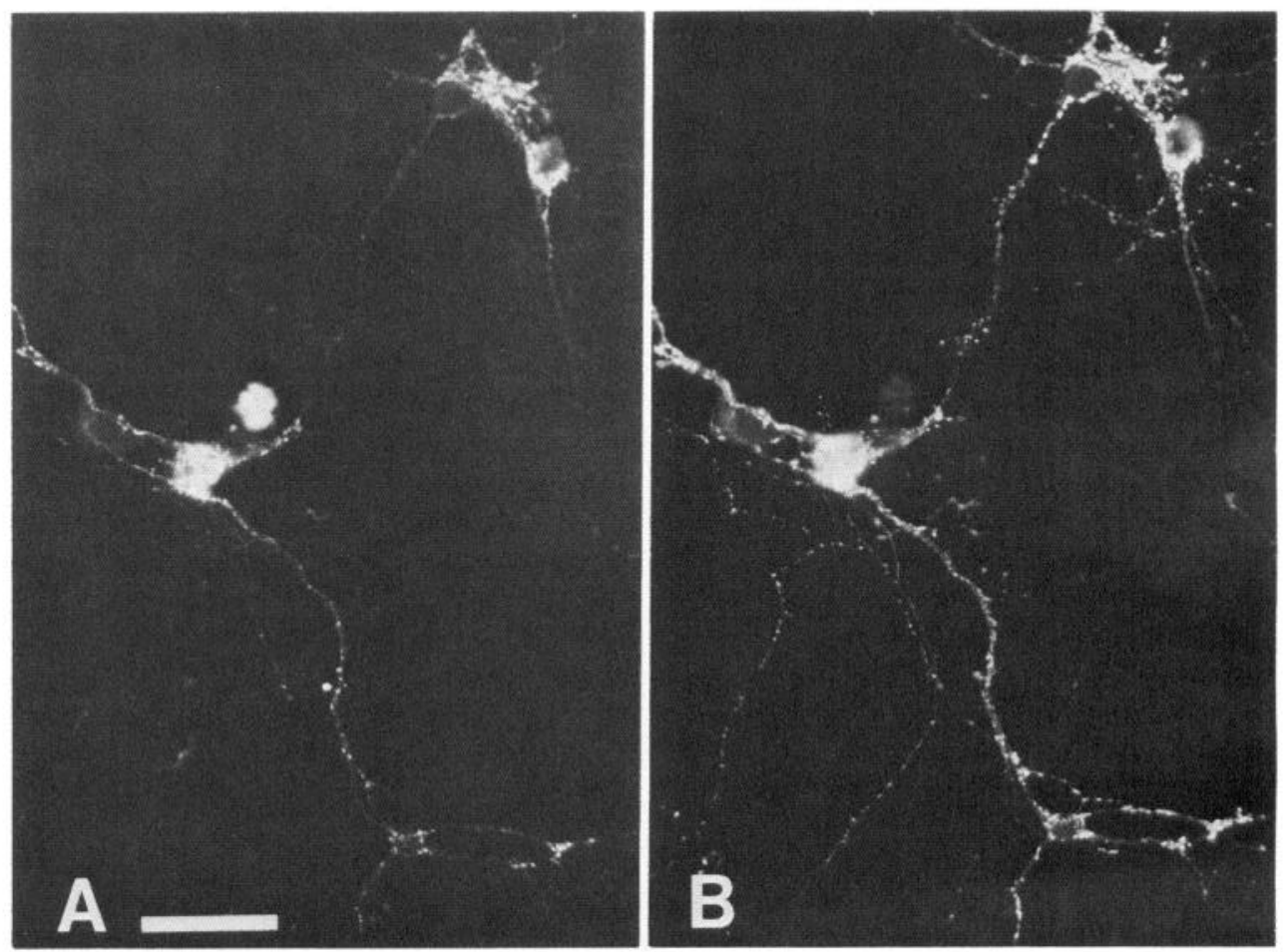

in vivo to enhance GAD staining (Oertel and Mugnaini, 1984), clearly enhanced the intensity of immunofluorescence in vitro but did not alter the percentage of GAD-6-containing neurons. In postnatal cultures, the proportion of neurons with immunoreactivity to GABA-5 is $90 \%$, compared with previously reported values of $46 \%$ from embryonic cultures (Surmeier et al., 1988). Since GABA levels increase from $20 \%$ of adult levels at embryonic day 15 to $60 \%$ at birth (Coyle and Enna, 1976), the postnatal cultures probably reflect a more accurate estimate of GABA-like immunoreactivity. The higher incidence of GABA-5 immunoreactivity $(90 \%)$ compared with GAD-6 immunoreactivity $(76 \%)$ has been observed previously (Nishimura et al., 1985; Mosinger and Yazulla, 1987). This may reflect a low level of cross-reactivity of the GABA-5 antibody (Wenthold et al., 1986), the early development of GABA uptake processes, or the fact that, developmentally, GAD lags behind GABA in reaching adult levels (Coyle and Enna, 1976). Indeed, the developmental changes in the pattern of GAD-6 immunoreactivity occur more slowly than those observed for GABA-5 (Fig. 10).

The appearance of synapsin I immunoreactivity in nerve cell bodies has been observed previously both in vivo (De Camilli and Greengard, 1986; Goldenring et al., 1986) and at early times in vitro (Weiss et al., 1986). In rat cerebellum, synapsin I is coded for by a $4.5 \mathrm{~kb}$ transcript that is expressed prior to postnatal day 7 and, subsequently, by a $3.4 \mathrm{~kb}$ transcript that peaks in its expression during synaptogenesis (Haas and DeGennaro, 1988). It is possible that the developmental changes observed in the pattern of synapsin I immunoreactivity correspond to this shift in mRNA expression.

\section{Inhibitory synaptic activity}

Striatal neurons maintained in tissue culture exhibit inhibitory synaptic currents sensitive to bicuculline which reverse at the GABA reversal potential. These "hyperpolarizing" synaptic re- sponses are produced by activation of $\mathrm{GABA}_{\mathrm{A}}$ type conductances. No "depolarizing" type GABA responses were observed. $\mathrm{GABA}_{\mathrm{B}}$ responses, activated by baclofen, were undetectable, as might be expected from the paucity of $\mathrm{GABA}_{\mathrm{B}}$ type receptors in striatal tissue in vivo (Wamsley et al., 1986).

These studies revealed striking parallel time courses of several aspects of the development of inhibitory synaptic function. During an apparent critical period between days 4 and 8 in vitro, neurons stabilize their position, both GAD and synapsin I immunoreactivity become colocalized to discrete sites along processes, inhibitory spontaneous synaptic activity becomes readily apparent, and GAD-containing processes appear encircling somata. Since the sensitivity to GABA remained constant throughout the culture lifetime, maturation of postsynaptic receptors is not considered to influence this developmental pattern. These experiments suggest that the development of functional inhibitory synaptic activity may, in part, be limited by the localization of the inhibitory transmitter synthetic enzyme, GAD, to presynaptic sites. Indeed, when neurons devoid of spontaneous IPSCs were subsequently stained with GAD-6, punctate immunoreactivity was not identifiable presynaptically along the soma or proximal processes.

In previous studies of cultured embryonic spinal cord, the onset of inhibitory synaptic transmission lags behind that of excitatory synaptic activity (Jackson et al., 1982; O'Brien and Fischbach, 1986). In cultures of neonatal striatum, both excitatory and inhibitory activity developed roughly in parallel. The more rapid onset of inhibitory activity in this study may reflect the higher levels of GAD present at birth than at embryonic ages (Coyle and Enna, 1976). Another difference in these preparations is the much higher percentage of inhibitory neurons in striatal cultures $(76 \%)$ compared with the estimated $15 \%$ in spinal cord tissue (Mugnaini and Oertel, 1985).

The frequency of spontaneous synaptic events did not become 

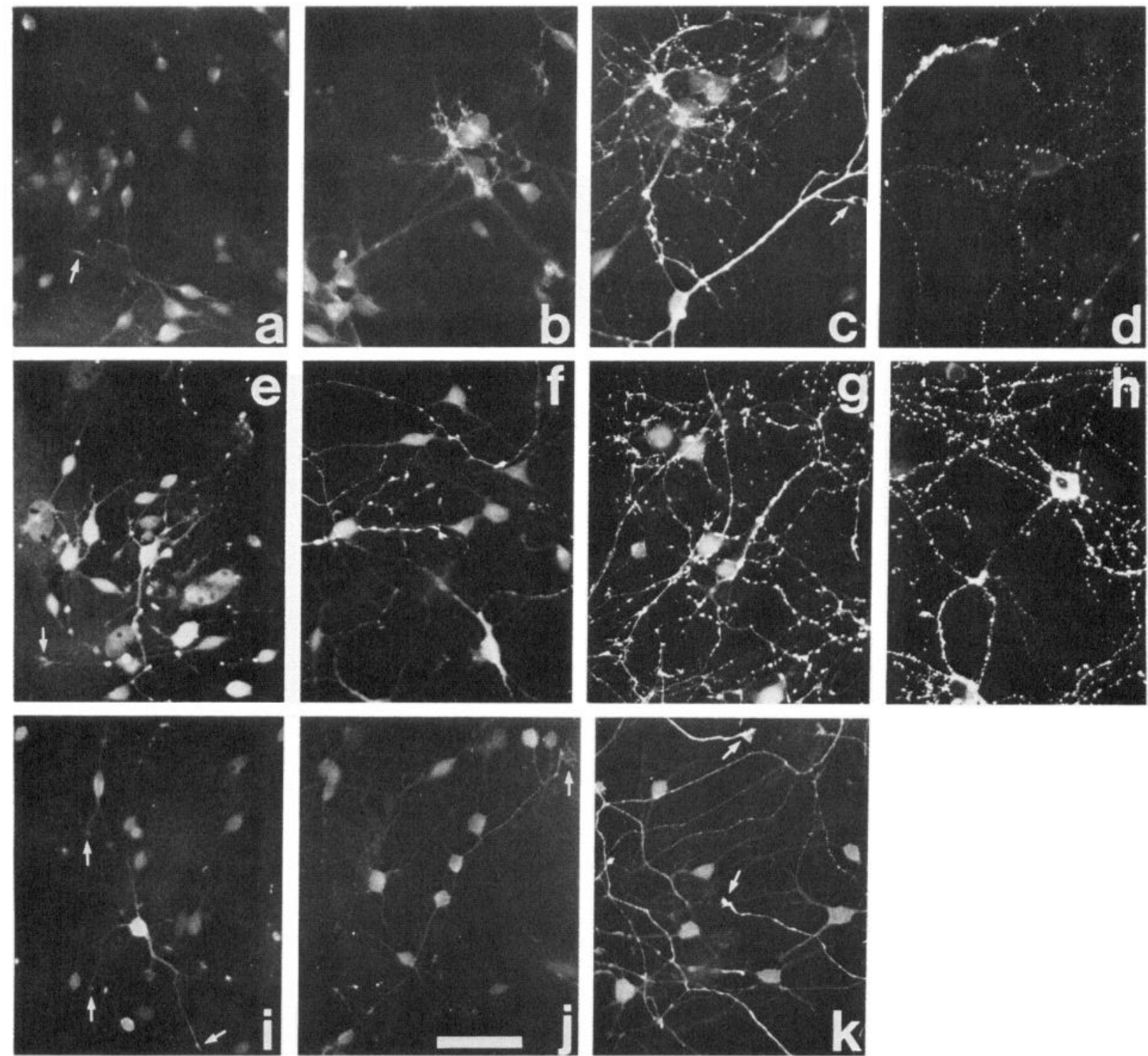

Figure 10. Developmental changes in the staining patterns of GAD-6 $(a-d)$, synapsin I $(e-h)$, and GABA-5 (i-k). Sister cultures were stained separately for each antibody on the following days: $a, e$, and $i, 1$ div; $b, f$, and $j, 4 \operatorname{div} ; c, g$, and $k, 11$ div; and $d$ and $h, 23$ div. Arrows indicate the presence of immunoreactivity in growth cones. All staining was visualized with fluorescein-conjugated secondary antibodies. Intensity of immunostaining increased with age for GAD-6 and GABA-5. Photographic exposures were slightly longer in $a$ and $i$ to capture the weaker initial immunoreactivity. Scale bar, $50 \mu \mathrm{m}$.

TTX sensitive until after 10 div. However, the effects of calcium channel blockers or varying calcium and magnesium concentrations have not been examined. Therefore, it is uncertain whether these TTX-insensitive events are true "miniature" IPSCs. Developmental increases of sodium current density have been reported in cultured spinal cord and cortical neurons (MacDermott and Westbrook, 1986; Huguenard et al., 1988). Similarly, overshooting action potentials are often difficult to evoke in younger striatal cultures. Calcium-dependent action potentials have been reported in striatal neurons in the presence of potassium channel blockers (Kita et al., 1985; Cherubini and Lanfumey, 1987), and the presence of local dendritic calcium spiking cannot be ruled out (Llinás et al., 1984). Thus, an apparent dissociation may exist between the onset of spontaneous synaptic release and the onset of sodium action potential driven synaptic events.
Of particular interest are the very earliest synaptic events observed as early as $24 \mathrm{hr}$ in vitro. These rare events may originate from the few neurons with punctate GAD-6 staining at this time period (Fig. 10). Since these occur when neurons are still quite mobile, it is possible that they occur at transient presynaptic sites or by some mechanism that does not require fully assembled presynaptic machinery. Motoneuron growth cones are capable of both evoked and spontaneous release of transmitter (Hume et al., 1983; Young and Poo, 1983; Sun and Poo, 1987). Since both GAD-6 and GABA-5 immunostaining appear in growth cones (Fig. 10), it is possible that growth cones from central neurons also release transmitter.

\section{Excitatory synaptic activity}

The presence of spontaneous glutamatergic excitatory activity is noteworthy among neurons from the caudate and putamen. 


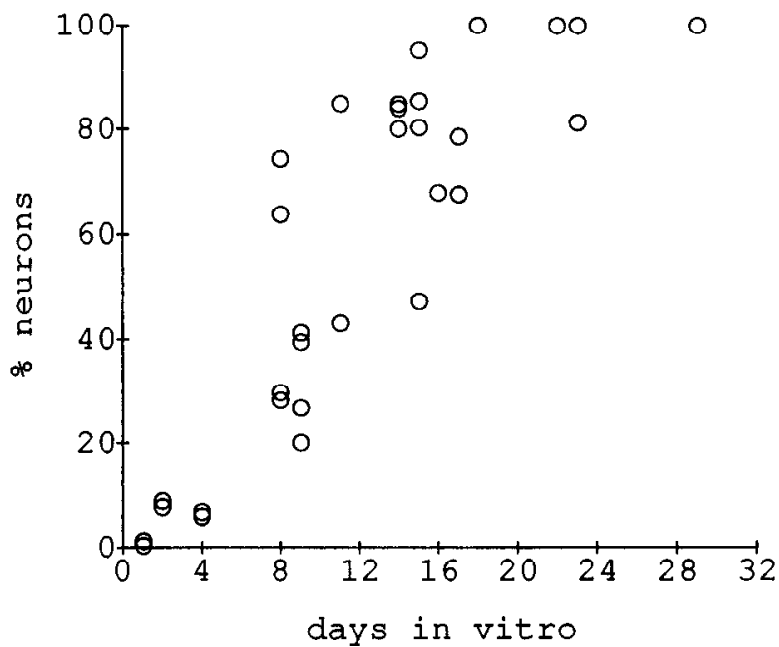

Figure 11. Percentage of CP neurons with punctate GAD-6 immunoreactivity in processes adjacent to their somas. Each data point represents the percentage of somas with punctate staining encountered in 10 microscope fields of one culture.

Glutamatergic afferents from cortex have been assumed to be the primary source of striatal excitatory activity (Hassler et al., 1982; Heimer et al., 1985). Experiments in striatal slices report excitatory events sensitive to the NMDA antagonist aminophosphonoheptanoic acid resulting from local field stimulation, presumably of endogenous striatal neurons (Lighthall and Kitai, 1983; Cherubini et al., 1988), but these may have resulted from fibers of passage. The observations in dissociated cultures indicate that striatal neurons are capable of using glutamate as a transmitter. It is unlikely that these are cortical neurons since great care was taken during dissections to exclude all extrastriatal tissue (Fig. 1). Although this expression could be an artifact of the culture environment, it is more likely an indication of the presence of glutamatergic neurons intrinsic to the striatum. Since $<1 \%$ of the cultured striatal neurons expressed choline acetyltransferase-like immunoreactivity or stained histochemically for acetylcholinesterase (unpublished observations), cholinergic excitatory activity was expected to be rare and was not studied.

The presence of GAD-6 immunoreactivity in 3 excitatory presynaptic neurons may represent a certain degree of falsepositivity since a low level of nonspecific background staining is always present with this technique. However, other neuronal somas in these cultures were clearly unstained. The most intriguing possibility is that these neurons represent a class of central neurons which are either pleuripotent or plastic with respect to their transmitter phenotype (Landis, 1984; Docherty et al., 1987). Cortical and striatal GABAergic neurons contain markers for neuropeptides (Hendry et al., 1984; Penny et al., 1986; Alho et al., 1988), and retinal amacrine cells can express both cholinergic and GABAergic traits (Brecha et al., 1988; Kosaka et al., 1988; Vaney and Young, 1988). An overlap of GABAergic and aspartate-containing neuronal populations has previously been suggested (Storm-Matisen and Ottersen, 1986). Considering the prevalence of excitatory activity in cultures with only $24 \%$ of the neurons lacking GAD-6 immunoreactivity, it is plausible that a population of GABAergic neurons may also express excitatory properties. Alternatively, a small number of excitatory neurons may innervate a large number of cells. The possibility that a single striatal neuron expresses both excitatory and inhibitory properties is currently being explored.

\section{References}

Alger, B. E., and R. A. Nicoll (1982) Pharmacological evidence for two kinds of GABA receptor on rat hippocampal pyramidal cells studied in vitro. J. Physiol. (Lond.) 328: 125-141.

Alho, H., C. Ferrarese, S. Vicini, and F. Vaccarino (1988) Subsets of GABAergic neurons in dissociated cell cultures of neonatal rat cerebral cortex show colocalization with specific modulator peptides. Dev. Brain Res. 39: 193-204.

Andersen, P., R. Dingledine, L. Gjerstad, I. A. Langmoen, and A. M. Laursen (1980) Two different responses of hippocampal pyramidal cells to application of $\gamma$-aminobutyric acid. J. Physiol. (Lond.) 305: 279-296.

Bignami, A., L. F. Eng, D. Dahl, and C. T. Uyeda (1972) Localization of the glial fibrillary acidic protein in astrocytes by immunofluorescence. Brain Res. 43: 429-435.

Bolam, J. P., J. F. Powell, S. Totterdell, and A. D. Smith (1981) The proportion of neurons in the rat neostriatum that project to the substantia nigra demonstrated using horseradish peroxidase conjugated with wheat germ agglutinin. Brain Res 220: 339-343.

Brecha, N., D. Johnson, L. Peichl, and H. Wassle (1988) Cholinergic amacrine cells of the rabbit retina contain glutamate decarboxylase and $\gamma$-aminobutyrate immunoreactivity. Proc. Natl. Acad. Sci. USA 85: 6187 .

Chang, Y.C., and D. I. Gottlieb (1988) Characterization of the proteins purified with monoclonal antibodies to glutamic acid decarboxylase. J. Neurosci. 8: 2123-2130.

Cherubini, E., and L. Lanfumey (1987) An inward calcium current underlying regenerative calcium potentials in rat striatal neurons in vitro enhanced by Bay K 8644. Neuroscience 21: 997-1005.

Cherubini, E., P. L. Herrling, L. Lanfumey, and P. Stanzione (1988) Excitatory amino acids in synaptic excitation of rat striatal neurones in vitro. J. Physiol. (Lond.) 400: 677-690.

Chesselet, M. R., L. Weiss, C. Wuenschell, A. J. Tobin, and H. U. Affolter (1987) Comparative distribution of mRNAs for glutamic acid decarboxylase, tyrosine hydroxylase, and tachykinins in the basal ganglia: An in situ hybridization study in the rodent brain. J. Comp. Neurol. 262: 125-140.

Coyle, J. T., and S. J. Enna (1976) Neurochemical aspects of the ontogenesis of GABAergic neurons in the rat brain. Brain Res. 111: 119-133.

De Camilli, P., and P. Greengard (1986) Synapsin I: A synaptic vesicleassociated neuronal phosphoprotein. Biochem. Pharmacol. 35: 43494357.

De Camilli, P., R. Cameron, and P. Greengard (1983) Synapsin I (Protein I), a nerve terminal-specific phosphoprotein. I. Its general distribution in synapses of the central and peripheral nervous system demonstrated by immunofluorescence in frozen and plastic sections. J. Cell Biol. 96: 1337-1354.

Docherty, M., H. F. Bradford, and J. Y. Wu (1987) Co-release of glutamate and aspartate from cholinergic and GABAergic synaptosomes. Nature 330: 64-66.

Dubinsky, J. M., M. Morgan, and G. D. Fischbach (1988) Variation among acetylcholine receptor clusters induced by ciliary ganglion neurons in vitro. Dev. Biol. 130: 209-219.

Fentress, J. C., B. B. Stanfield, and W. M. Cowan (1981) Observations on the development of the striatum in mice and rats. Anat. Embryol. 163: 275-298.

Gahwiler, B. H., and D. A. Brown (1985) GABA $_{\mathrm{B}}$-receptor-activated $\mathrm{K}^{+}$current in voltage-clamped $\mathrm{CA}_{3}$ pyramidal cells in hippocampal cultures. Proc. Natl. Acad. Sci. USA 82: 1558-1562.

Goldenring, J. R., R. S. Lasher, M. L. Vallano, T. Ueda, S. Naito, N. H. Sternberger, L. A. Sternberger, and R. J. DeLorenzo (1986) Association of synapsin I with neuronal cytoskeleton. Identification in cytoskeletal preparations in vitro and immunocytochemical localization in brain of synapsin I. J. Biol. Chem. 261: 8495-8504.

Haas, C. A., and L. J. DeGennaro (1988) Multiple synapsin I messenger RNAs are differentially regulated during neuronal development. J. Cell Biol. 106: 195-203.

Hamill, O. P., A. Marty, E. Neher, B. Sakmann, and F. J. Sigworth (1981) Improved patch clamp techniques for high-resolution current recordings from cells and cell-free membrane patches. Pfluegers Arch. 391: 85-100. 
Hassler, R., P. Hang, C. Nitsch, J. S. Kim, and K. Poik (1982) Effect of motor and premotor cortex ablation on concentrations of amino acids, monoamines, and acetylcholine and on the ultrastructure in rat striatum. A confirmation of glutamate as the specific corticostriatal transmitter. J. Neurochem. 38: 1087-1098.

Heimer, L., G. F. Alheid, and L. Zaborszky (1985) Basal ganglia. In The Rat Nervous System, Vol. 1, G. Paxinos, ed., pp. 37-86, Academic, Sydney.

Hendry, S. H. C., E. G. Jones, J. DeFelipe, D. Schmechel, C. Brandon, and P. C. Emson (1984) Neuropeptide-containing neurons of the cerebral cortex are also GABAergic. Proc. Natl. Acad. Sci. USA 81: 6526-6530.

Hirano, T., Y. Kubo, and M. M. Wu (1986) Cerebellar granule cells in culture: Monosynaptic connections with Purkinje cells and ionic currents. Proc. Natl. Acad. Sci. USA 83: 4957-4961.

Huettner, J. E., and R. W. Baughman (1986) Primary culture of identified neurons from the visual cortex of postnatal rats. J. Neurosci. 6: 3044-3060.

Huguenard, J. R., and B. E. Alger (1986) Whole-cell voltage-clamp study of the fading of GABA-activated currents in acutely dissociated hippocampal neurons. J. Neurophysiol. 56: 1-17.

Huguenard, J. R., O. P. Hamill, and D. A. Prince (1988) Developmental changes in $\mathrm{Na}^{+}$conductances in rat neocortical neurons: Appearance of a slowly inactivating component. J. Neurophys. 59: 778795.

Hume, R. I., L. W. Role, and G. D. Fischbach (1983) Acetylcholine release from growth cones detected with patches of acetylcholine receptor-rich membranes. Nature 305: 632 .

Jackson, M. B., H. Lecar, D. E. Brenneman, S. Fitzgerald, and P. G, Nelson (1982) Electrical development in spinal cord cell culture. J. Neurosci. 2: 1052-1061.

Kita, H., and S. T. Kitai (1988) Glutamate decarboxylase immunoreactive neurons in rat neostriatum: Their morphological types and populations. Brain Res. 447: 346-352.

Kita, H., T. Kita, and S. T. Kitai (1985) Regenerative potentials in rat neostriatal neurons in an in vitro slice preparation. Exp. Brain Res. 60: 63-70.

Kosaka, T., M. Tauchi, and J. L. Dahl (1988) Cholinergic neurons containing GABA-like and/or glutamic acid decarboxylase-like immunoreactivities in various brain regions of the rat. Exp. Brain Res. 70: 605-617.

Landis, S. C. (1984) Neurotransmitter plasticity and coexistence during the development of cholinergic sympathetic neurons in culture and in vivo. In Coexistence of Neuroactive Substances in Neurons, V. Chan-Palay and S. Palay, eds., pp. 205-216, Wiley, New York.

Lighthall, J. W., and S. T. Kitai (1983) A short duration GABAergic inhibition in identified neostriatal medium spiny neurons: in vitro slice study. Brain Res. Bull. 11: 103-110.

Lighthall, J. W., M. R. Park, and S. T. Kitai (1981) Inhibition in slices of rat neostriatum. Brain Res. 212: 182-187.

Llinás, R., S. A. Greenfield, and H. Jahnsen (1984) Electrophysiology of pars compacta cells in the in vitro substantia nigra-a possible mechanism for dendritic release. Brain Res. 294: 127-132.

Loopuijt, L. D., and D. Van der Kooy (1985) Organization of the striatum: Collateralization of its efferent axons. Brain Res. 348: 8699.

MacDermott, A., and G. Westbrook (1986) Early development of voltage-dependent sodium currents in cultured mouse spinal neurons. Dev. Biol. 113: 317-326.

Morrison, R. S., H. I. Kornblum, F. M. Leslie, and R. A. Bradshaw (1987) Trophic stimulation of cultured neurons from neonatal rat brain by epidermal growth factor. Science 238: 72-75.

Mosinger, J., and S. Yazulla (1987) Double-label analysis of GAD. and GABA-like immunoreactivity in the rabbit retina. Vis. Res. 27 23-30.

Mueller, A. L., J. S. Taube, and P. A. Schwartzkroin (1984) Devel- opment of hyperpolarizing inhibitory postsynaptic potentials and hypcrpolarizing response to $\gamma$-aminobutyric acid in rabbit hippocampus studied in vitro. J. Neurosci. 4: 860-867.

Mugnaini, E., and W. H. Oertel (1985) An atlas of the distribution of GABAergic neurons and terminals in the rat CNS as revealed by GAD immunohistochemistry. In Handbook of Chemical Neuroanatomy, Vol. 4: GABA and Neuropeptides in the CNS, A. Bjorklund and T. Hökfelt, eds., pp. 436-608, Elsevier, Amsterdam.

Nakajima, Y., S. Nakajima, R. J. Leonard, and K. Yamaguchi (1986) Acetylcholine raises excitability by inhibiting the fast transient potassium current in cultured hippocampal neurons. Proc. Natl. Acad. Sci. USA 83: 3022-3026.

Newberry, N. R., and R. A. Nicoll (1985) Comparison of the action of baclofen with gamma-aminobutyric acid on rat hippocampal pyramidal cells in vitro. J. Physiol. (Lond.) 360: 161-185.

Nishimura, Y., S. L. Schwartz, and P. Rakic (1985) Localization of $\gamma$-aminobutyric acid and glutamic acid decarboxylase in rhesus monkey retina. Brain Res. 359: 351-355.

Nobel, M., J. Fok-Seang, and J. Cohen (1984) Glia are a unique substrate for the in vitro growth of central nervous system neurons. J. Neurosci. 4: 1892-1903.

O'Brien, R. J., and G. D. Fischbach (1986) Excitatory synaptic transmission between interneurons and motoneurons in chick spinal cord cell cultures. J. Neurosci. 6: 3284-3289.

Oertel, W. H., and E. Mugnaini (1984) Immunocytochemical studies of GABAergic neurons in rat basal ganglia and their relations to other neuronal systems. Neurosci. Lett. 47: 233-238.

Paxinos, G., and C. Watson (1986) The Rat Brain in Stereotaxic Coordinates, 2nd ed., Academic, Sydney.

Penny, G. R., S. Afsharpour, and S. T. Kitai (1986) The glutamate decarboxylase-leucine enkephalin-, methionine enkephalin- and substance P-immunoreactive neurons in the neostriatum of the rat and cat: Evidence for partial population overlap. Neuroscience 17: 10111045 .

Storm-Matisen, J., and O. P. Ottersen (1986) Antibodies against amino acid neurotransmitters. In Neurohistochemistry: Modern Methods and Applications, P. Panual et al., eds., pp. 107-136, Liss, New York.

Sun, Y. A., and M. M. Poo (1987) Evoked release of acetylcholine from the growing embryonic neuron. Proc. Natl. Acad. Sci. USA 84: 2540-2544.

Surmeier, D. J., H. Kita, and S. T. Kitai (1988) The expression of gamma-aminobutyric acid and leu-enkephalin immunoreactivity in primary monolayer cultures of rat striatum. Dev. Brain Res. 42: 265282.

Vaney, D. I., and H. M. Young (1988) GABA-like immunoreactivity in cholinergic amacrine cells of the rabbit retina. Brain Res. 438:369373.

Wamsley, J. K., D. R. Gehlert, and R. W. Olsen (1986) The benzodiazepine/barbiturate-sensitive convulsant/GABA receptor/chloride ionophore complex: Autoradiographic localization of individual components. In Benzodiazepine/GABA Receptors and Chloride Channels: Structural and Functional Properties, R. W. Olsen and J. C. Venter, eds., pp. 299-313, Liss, New York.

Weiss, S., J. P. Oin, M. Sebben, D. E. Kemp, R. Sladeczek, J. Gabrion, and J. Bockaert (1986) Synaptogenesis of cultured striatal neurons in serum-free medium: A morphological and biochemical study. Proc. Natl. Acad. Sci. USA 83: 2238-2242.

Wenthold, R. J., J. M. Zempel, M. H. Parakkal, K. A. Reeks, and R. A. Altschuler (1986) Immunocytochemical localization of GABA in the cochlear nucleus of the guinea pig. Brain Res. 380: 7-18.

Yamada, K., J. M. Dubinsky, and S. M. Rothman (1989) Quantitative physiological characterization of a quinoxalinedione non-NMDA receptor antagonist. J. Neurosci. 9: 3230-3236.

Young, S. H., and M. M. Poo (1983) Topographical rearrangement of ACh receptors alters channel kinetics. Nature 305: 634-637. 